\title{
Congenital Anatomical Variant with Cranial Origin of Internal Iliac Arteries
}

\author{
Umberto G. Rossi, MD, EBIR ${ }^{1,2}$ Anna M. lerardi, MD ${ }^{2}$ Maurizio Cariati, MD² \\ ${ }^{1}$ Department of Diagnostic Imaging, Interventional Radiology Unit, \\ Ente Ospedaliero Galliera Hospital, Genova, Italy \\ 2 Department of Diagnostic and Therapeutic Advanced Technology, \\ Diagnostic and Interventional Radiology Unit, Azienda Socio \\ Sanitaria Territoriale Santi Paolo and Carlo Hospital, Milan, Italy \\ Address for correspondence Umberto G. Rossi, MD, EBIR, \\ Department of Diagnostic Imaging, Interventional Radiology Unit, \\ Ente Ospedaliero Galliera Hospital, Mura delle Cappuccine, 14, 16128, \\ Genova, Italy \\ (e-mail: urossi76@hotmail.com; umberto.rossi@galliera.it).
}

Aorta (Stamford) 2021;9:86-87.
Abstract
Keywords
- iliac artery
- vascular
- variant
- congenital
- anatomy
- imaging

We report the case of a 73-year-old male who underwent abdominal multidetector computed tomography with vascular reconstruction that highlighted a congenital variant of iliac arteries. Iliac artery anatomical variants are exceedingly rare and only a few cases have been reported in the literature.
We present a case of a 73-year-old male who presented to our emergency department for abdominal trauma due to a car incident. He underwent abdominal multidetector computed tomography that excluded abdominal traumatic pathologies. Vascular coronal volume rendering reconstruction highlighted an asymptomatic congenital anatomical variant, with cranial origin of internal iliac arteries (-Fig. 1). This proximal origin of both internal iliac arteries was associated with a reduced length of both common iliac arteries: right one of $16 \mathrm{~mm}$ and left one of $4 \mathrm{~mm}$. The patient showed no traumatic signs, and he was discharged after 6 hours of observation.

Congenital variants of the iliac arteries are exceedingly rare, and only a few cases have been reported in the literature. ${ }^{1-3}$ Iliac vasculature variants arise during the embryological process, starting in the fourth week of gestation. ${ }^{1}$ These iliac variants can be classified into three categories: $^{2}(1)$ group 1 includes variants of origin and/or course; (2) group 2 involves hypoplasia or atresia, with a persistent sciatic artery; and (3) group 3 represents isolated hypoplasia or atresia. Group 1 variants are generally coincidental findings because the subjects are asymptomatic. ${ }^{1-3}$

With an increase in noninvasive diagnostic vascular imaging, thoracoabdominal vascular anomalies are seen with greater frequency, ${ }^{3-6}$ also in asymptomatic patients. Knowledge of possible variations in iliac vascular anatomy, in terms of origin and course or hypoplasia, is crucial for patients who are candidates for abdominal vascular and endovascular treatments. received

November 25, 2019

accepted after revision

November 11, 2020

published online

October 7, 2021
DOI https://doi.org/

10.1055/s-0041-1725089.

ISSN 2325-4637.

\section{(c) 2021. The Author(s).}

This is an open access article published by Thieme under the terms of the Creative Commons Attribution License, permitting unrestricted use, distribution, and reproduction so long as the original work is properly cited. (https://creativecommons.org/licenses/by/4.0/)

Thieme Medical Publishers, Inc., 333 Seventh Avenue, 18th Floor, New York, NY 10001, USA 


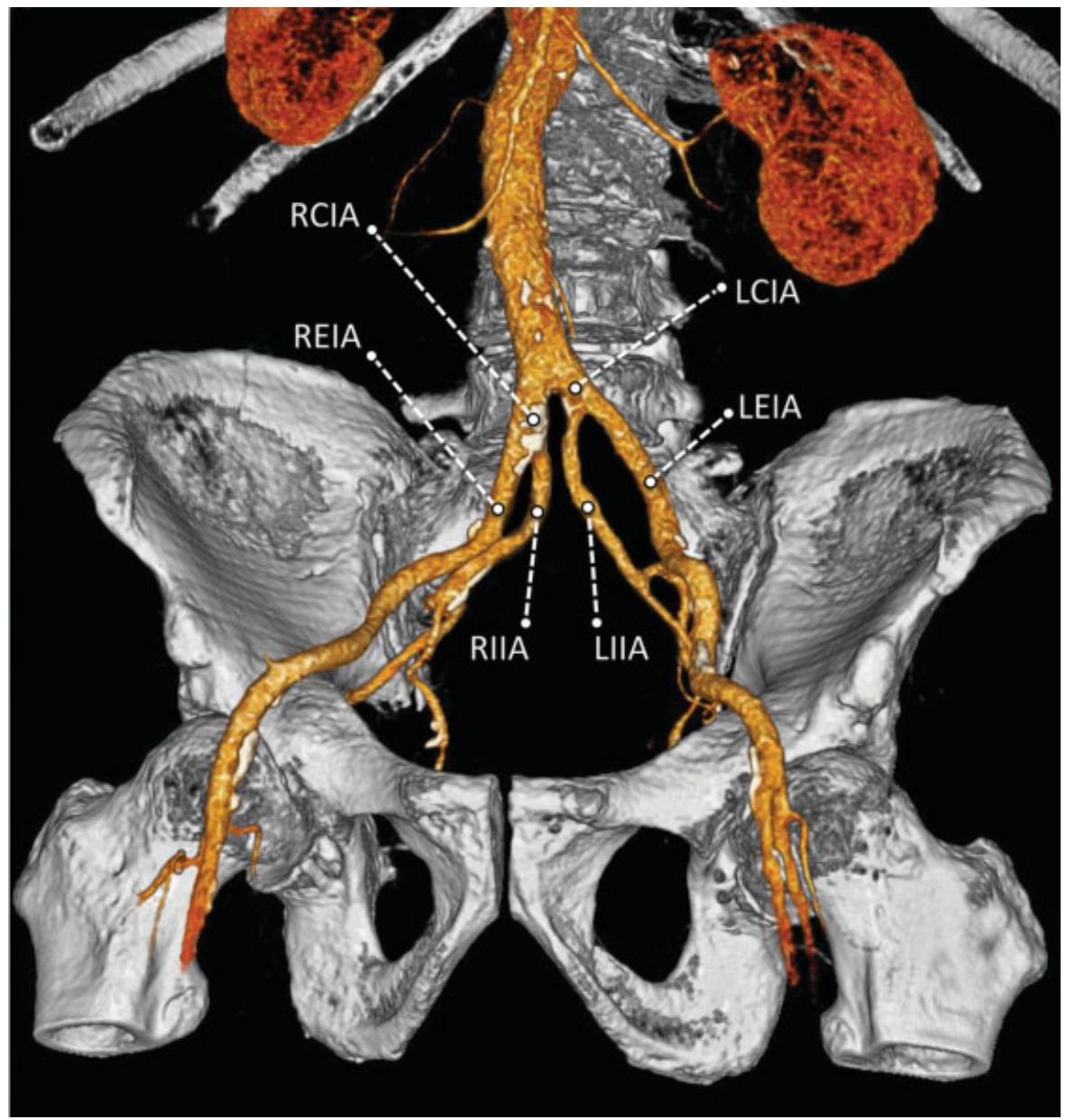

Fig. 1 Multidetector computed tomography angiography coronal volume reconstruction demonstrating the presence of a congenital anatomical variant, with cranially displaced origin of the internal iliac arteries (right internal iliac artery [RIIA] and left internal iliac artery [LIIA]), reduced length of both common iliac arteries (right common iliac artery [RCIA] and left common iliac artery [LCIA]), and increased length of both external iliac arteries (right external iliac artery [REIA] and left external iliac artery [LEIA]).

\section{Funding}

This research was funded solely through institutional sources.

\section{Conflict of Interest}

The authors declare no conflict of interest related to this article.

\section{Acknowledgments}

None.

\section{References}

1 Greebe J. Congenital anomalies of the iliofemoral artery. J Cardiovasc Surg (Torino) 1977;18(03):317-323
2 Tamisier D, Melki JP, Cormier JM. Congenital anomalies of the external iliac artery: case report and review of the literature. Ann Vasc Surg 1990;4(05):510-514

3 Green CS, Helmy MA. Novel, congenital iliac arterial anatomy: Absent common iliac arteries and left internal iliac artery. Radiol Case Rep 2015;9(03):978

4 Rossi UG, Rollandi GA. Thoracic renal artery. Aorta (Stamford) 2019;7(03):96-97

5 Valdata A, Paparo F, Rossi UG. Five branches variant of the aortic arch. J Vasc Interv Radiol 2019;30(01):42

6 Einstein EH, Song LH, Villela NL, et al. Anomalous origin of the left vertebral artery from the aortic arch. Aorta (Stamford) 2016;4 (02):64-67 